\title{
Instrumentos de gestão ambiental em municípios do semiárido brasileiro*
}

\section{Cecília Barreto Rodrigues ${ }^{1}$, Marcio Regys Rabelo de Oliveira ${ }^{1}$, Patrícia Verônica Pinheiro Sales Lima², Francisco Casimiro Filho ${ }^{3}$}

${ }^{1}$ Estudante de Agronomia. Universidade Federal do Ceará.

${ }^{2}$ Professora do Programa de Pós-Graduação em Desenvolvimento e Meio Ambiente. Bolsista CNPq. Universidade Federal do Ceará. Campus do Pici. Bloco 902. FortalezaCE, Brasil. (CEP 60455-970).*E-mail: patricialima@ufc.br.

${ }^{3}$ Professor do Programa de Pós-Graduação em Desenvolvimento e Meio Ambiente. Universidade Federal do Ceará. Campus do Pici. Bloco 902. Fortaleza-CE, Brasil.

Resumo. O objetivo deste estudo é analisar o nível de implementação de instrumentos de gestão ambiental nos municípios do Semiárido Brasileiro (SAB). Para tanto foi adotado como estimativa um índice agregado de gestão ambiental (IGA), construído a partir de indicadores disponibilizados pelo Instituto de Geografia e Estatística do Brasil (IBGE). Em seguida os municípios foram agrupados em três classes segundo semelhanças quanto ao IGA. Os resultados mostraram que há um nível muito baixo de implementação de instrumentos de gestão ambiental, o que reduz a capacidade do município de preservar, conservar e recuperar os recursos naturais locais em atendimento às demandas da população.

Palavras-chaves: Planejamento público; Políticas públicas; Meio ambiente.

Abstract. Environmental management tools in the municipalities of Brazilian semi-arid. The aim of this study is to analyze the level of implementation of environmental management tools in the municipalities of Brazilian Semi-Arid (SAB). To this end it was adopted as proxy an environmental management index (EMI), constructed from indicators provided by the Institute of Geography and Statistics of Brazil (IBGE). After that, the municipalities were grouped into three classes according to similarities according to EMI. The results showed that there is a very low level of implementation of environmental management tools which reduces the municipality's ability to preserve, conserve and restore the local natural resources to meet the population's demands.

Keywords: Public planning; Public policies; Environment.
Recebido: 29/07/2016

Aceito: 02/09/2016

Publicado: 30/09/2016

Acesso Aberto Artigo completo

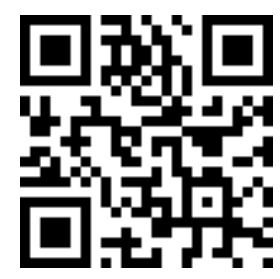

ORCID

(1) 0000-0002-0261-6445

Cecília Barreto

Rodrigues

(D) 0000-0002-1150-1498

Marcio Regys Rabelo de Oliveira

(1) 0000-0002-6622-3640 Patrícia Veronica Pinheiro Sales Lima (1) 0000-0001-9196-948X Francisco Casimiro Filho

\footnotetext{
*Apresentado no V Congresso Brasileiro de Educação Ambiental Aplicada e Gestão Territorial, Fortaleza/CE, 8 a 11/06/2016.
} 


\section{Introdução}

No Brasil, o semiárido é uma das áreas mais vulneráveis aos problemas ambientais (IPCC, 2007; Marengo et al., 2011). Essa condição é agravada por suas características naturais e socioeconômicas (Andrade et al., 2013). Esse cenário é amplamente favorável à expansão dos processos de degradação dos recursos naturais dos municípios da região.

Podemos considerar como consequências graves de um solo degradado a perda progressiva da sua fertilidade mineral, a erosão física e silenciosa, aliada a perda de sua capacidade de manter-se biodiverso. Estas condições são potencializadas quando aliada a uma situação de escassez hídrica que grassa o Nordeste do país. Neste cenário, torna-se fundamental compreender que nessas regiões mais afetadas, existe a necessidade da implementação tanto de ações de recuperação ambiental quanto de educação e conscientização da população sobre o uso da terra e o seu manejo. Esta contribuição permitirá que os efeitos da degradação, hoje já evidentes em muitos municípios, sejam desde já mitigados.

A preocupação com o meio ambiente está implícita na Constituição Federal (CF) de 1988, art. 225, quando deixa claro que todo cidadão tem direito a um ambiente ecologicamente equilibrado, o qual deve ser preservado para as gerações futuras tanto pela sociedade quanto pelo poder público, sendo este exercido nos âmbitos federal, estadual e municipal de governo.

Embora não exista clareza sobre as competências específicas de cada esfera de governo na CF, em seu art. 30, VIII, a CF impõe que é responsabilidade do município "promover, no que couber adequado ordenamento territorial, mediante planejamento e controle do uso, do parcelamento e da ocupação do solo". É visível uma tendência descentralizadora por parte do Governo Federal, que empodera os municípios com a competência para o planejamento e a gestão de seu território.

As novas competências atribuídas aos municípios revestem-se de importância especial no semiárido brasileiro, haja vista a existência de fatores socioeconômicos e climáticos que contribuem para o aumento da vulnerabilidade local: ocupação desordenada do território, agravamento dos processos de degradação ambiental e um elevado percentual de pobreza. Ressalte-se, ainda, o fato do município ser o ente federativo mais próximo da população e de seus problemas. De acordo com Miranda (2012), o governo municipal adquire um papel central como stakeholder, em decorrência do contato em primeira instância com os problemas urbanoambiental de sua população.

$\mathrm{Na}$ ausência de instrumentos de gestão ambiental municipal, as políticas públicas para o meio ambiente podem ser enfraquecidas por não encontrarem condições favoráveis para a sua efetividade: integração entre secretarias municipais, mecanismos de fiscalização, engajamento da população via conselhos municipais. Para que as competências municipais sejam operacionalizadas é necessário que as prefeituras disponham de um ambiente institucional adequado, com pessoas capacitadas e implementação de instrumentos de gestão municipal. Segundo Oliveira et al. (2015) estudos mostram que a implementação de instrumentos de gestão ambiental pelas prefeituras ainda é muito baixa, o que pode interferir no bem estar da população. Esse baixo nível de implementação foi verificado nas áreas de saneamento básico (Carvalho et al., 2013), segurança pública (Araújo Sobrinho et al., 2014) e direitos humanos (Sousa et al., 2015).

A realidade observada nos municípios brasileiros requer avanços e a reflexão sobre a urgente necessidade de adoção de práticas de uma boa gestão do meio ambiente. Acredita-se que seja necessária a elaboração de estudos que apontem as demandas básicas quanto aos instrumentos municipais de gestão e estabeleçam prioridades servindo, assim, de subsídios para os planejadores de políticas públicas. Trata-se de identificar carências para que sejam tomadas decisões que servirão de alicerce para mudanças mais substanciais no sentido de aprimorar o uso e 
ocupação do solo, da água e a vegetação de uma área, pois só assim será possível promover o uso sustentável, isto é, o uso consciente e conservativo dos recursos naturais, principalmente nas áreas mais vulneráveis.

Nessa perpectiva, o presente estudo busca analisar o nível de implementação de instrumentos de gestão ambiental nos municípios do Semiárido Brasileiro (SAB). Como contribuições destacam-se: i) a possibilidade de análise de todo Semiárido Brasileiro (SAB), haja vista a adoção da escala municipal e, consequentemente, dos 1.133 aí inseridos ii) a sistematização de informações importantes para a compreensão do papel dos municípios na minimização dos problemas ambientais do $\mathrm{SAB}$; iii) a identificação dos municípios com menores e maiores níveis de implementação de instrumentos de gestão ambiental; iv) a identificação dos instrumentos mais e menos implementados.

\section{municípios}

A gestão ambiental e o papel dos

Com grande atenção voltada para a temática gestão ambiental e sustentabilidade, atualmente essa questão vem abrangendo um amplo campo de discussões sejam elas políticas, corporativas, econômicas, sociais e acadêmicas (Chaves et al., 2013). No Brasil, o crescimento do movimento ambientalista ganhou força no momento em que se incorporou à Constituição Brasileira de 1988 o artigo 225, o qual consta um compromisso do país com o desenvolvimento sustentável e com a manutenção do meio ambiente equilibrado (Sabbagh, 2011). De acordo com esse artigo 225, todos têm direito ao meio ambiente ecologicamente equilibrado, bem de uso comum do povo e essencial à sadia qualidade de vida, impondo-se ao Poder Público e à coletividade o dever de defendê-lo e preservá-lo para as presentes e futuras gerações. Seguindo este preceito pode-se entender por "gestão ambiental" como sendo uma administração dos recursos ambientais, com o objetivo de sua conservação de modo a garantir que as gerações posteriores encontrem um ambiente compatível com suas necessidades.

Tinoco e Kraemer (2004) conceituam a gestão ambiental como uma estrutura de visão sistêmica, que agrega planejamento, responsabilidades, práticas, procedimentos e processos com o propósito de haver uma mobilização interna e externa para que se possa atingir a qualidade ambiental almejada.

A gestão ambiental deve direcionar as ações desenvolvidas na exploração dos recursos naturais de modo a conduzir as atividades antrópicas a fim de que sejam menos agressivas e mais condizentes com a atual situação de vulnerabilidade desses municípios. Assim, entende-se que a gestão ambiental proporciona um ambiente favorável à implementação de políticas ambientais, as quais podem ser caracterizadas em relação ao seu nível de caráter e abrangência. Na ausência de instrumentos eficientes de gestão ambiental, a degradação dos recursos naturais alcança níveis alarmantes de insustentabilidade, ameaçando a população regional e comprometendo a estabilidade socioeconômica dos municípios assolados pelo clima semiárido.

Conforme Moraes (2003), a fim de conter os níveis de degradação é essencial que a gestão ambiental seja incorporada pelo governo municipal, principal detentor dos equipamentos e da infraestrutura que modelam o uso dos recursos naturais pela sociedade. A preservação ambiental é responsabilidade de todos, no entanto restringindo a análise ao papel do poder municipal, percebe-se que a atuação deste será potencializada se houver uma estrutura administrativa favorável para lidar com os problemas ambientais locais.

Entende-se por estrutura administrativa favorável, pelo menos a existência de instrumentos de gestão que auxiliem na elaboração e implementação de políticas públicas de combate à degradação ambiental como, por exemplo, o Conselho Municipal de Meio Ambiente, Fundo Municipal de Meio Ambiente, Financiamento de Ações e Projetos para Questões Ambientais, Cooperação com órgão Estadual para licenciamento 
ambiental, Consórcio Intermunicipal, Existência de Comitê de Bacia Hidrográfica, isto é, mecanismos capazes de administrar de maneira mais específica os recursos ambientais como solo, água e vegetação do município, de maneira a sinergizar as tomadas de decisões.

Dessa forma, para auxiliar nas medidas preventivas e reparadoras de preservação ao meio ambiente buscam-se a sistematização de procedimentos técnicos e administrativos para assegurar a melhoria e o aprimoramento contínuo do desempenho ambiental de um empreendimento ou de uma área a ser protegida e, em decorrência, obter o reconhecimento de conformidade das medidas e práticas adotadas, procedimentos estes denominados de Instrumentos de Gestão Ambiental (Bitar e Ortega, 1998). Assim, a avaliação do grau de implantação dos instrumentos de gestão ambiental nos municípios do Semiárido Brasileiro (SAB), adota a pressuposição que a gestão ambiental deve favorecer a elaboração/implementação/execução de políticas públicas voltadas para o uso racional dos recursos naturais, de modo a reduzir a pressão antrópica e a degradação, presentes em todo território semiárido.

Brose (2004) corrobora que sem o conhecimento há má utilização dos recursos naturais, agressão ao meio ambiente e as pessoas terão limitadas as possibilidades de intervir sobre a sua realidade. Nesse sentido, na busca por mitigar os efeitos desse processo ou até mesmo revertê-lo, é que são adotados instrumentos de gestão como alternativa à passividade e a negligência dos gestores perante 0 ambiente.

A gestão ambiental refere-se à forma como o governo conduz e controla o uso dos recursos naturais por meio de diferentes instrumentos. Dentre tais instrumentos, no âmbito da gestão municipal o Instituto Brasileiro de Geografia e Estatística, na pesquisa Perfil dos Municípios Brasileiros, destaca os conselhos municipais de meio ambiente, o fundo municipal de meio ambiente, instrumentos de cooperação com órgão estadual para licenciamento ambiental, consórcios intermunicipais e comitês de bacias hidrográficas (IBGE, 2010). Estes instrumentos são descritos a seguir:

I. Conselho Municipal do Meio Ambiente - "Conselhos de meio ambiente são órgãos colegiados normativos (propõem normas e diretrizes relativas à gestão ambiental), paritários (com igualdade de representação), de caráter consultivo (emitem opinião e parecer; indicam ações ou políticas) e deliberativo (têm poder de decisão sobre a implementação de políticas ou a administração de recursos)" (Perez, 2015, p. 6). Os conselhos municipais assessoram a prefeitura nos assuntos referentes ao meio ambiente, cabendo aos mesmos i) a proposição de políticas e a fiscalização do seu cumprimento; ii) a promoção da educação ambiental, iii) a sugestão de criação de normas legais e adequação de leis e iv) a opinião sobre políticas que possam impactar o meio ambiente no município (MMA, 2016).

II. Fundo Municipal do Meio Ambiente - é uma fonte de recursos cuja finalidade é apoiar ações voltadas ao uso racional dos recursos naturais, além da conservação, preservação e recuperação da qualidade ambiental, seguindo as diretrizes da Política Nacional do Meio Ambiente (Carvalho et al., 2005). Os fundos municipais foram legitimados na Lei $n^{\circ}$ 9.605/1998, em seu art. 73, que estabelece a sua formação a partir de valores arrecadados em decorrência de multas aplicadas e da cobrança de taxas pelo licenciamento ambiental, podendo também receber recursos externos (Milaré, 1999).

III. Instrumentos de cooperação com órgão estadual para licenciamento ambiental - O licenciamento ambiental é um procedimento pelo qual a administração pública analisa a viabilidade de implementação de um projeto quanto aos danos que o mesmo pode causar ao ambiente. Segundo Vieira e Weber (2008, p. 6):

Os Municípios podem realizar o licenciamento das atividades consideradas de impacto local, considerando-se a natureza da atividade, suas características e 
complexidade, Ainda recai sobre os Municípios a competência de licenciar atividades e empreendimentos que lhe forem delegadas pelo Estado por instrumento legal ou convênio.

IV. Consórcio Intermunicipal Consiste em um grupo de municípios reunidos com o objetivo de realizar ações conjuntas de modo a otimizar resultados que não seriam alcançados por um ou outro município caso agisse de forma isolada ou demandariam valores mais elevados de recursos financeiros (Vaz, 1997). No âmbito ambiental exemplos de consórcios intermunicipais são observados na solução de problemas hídricos, de saneamento básico, resíduos sólidos.

\section{Comitê de Bacias} Hidrográficas - faz parte do Sistema Nacional de Gerenciamento de Recursos Hídricos contribuindo para que todos os setores da sociedade com interesse sobre a água na bacia tenham representação e poder de decisão sobre sua gestão a partir da sua composição diversificada e democrática. Nele são tomadas as decisões políticas sobre a utilização da água (Milaré, 2005). O comitê é composto por representantes das três esferas governamentais; dos usuários das águas e das sociedades civis de recursos hídricos com a competência principalmente de aprovar o Plano de Recursos Hídricos da Bacia; arbitrar conflitos pelo uso da água, em primeira instância administrativa; estabelecer mecanismos e sugerir os valores da cobrança pelo uso da água, entre outros (ANA, 2011).

Os instrumentos citados não são únicos. No entanto, representam possibilidades a serem usadas pelo município no planejamento ambiental. A sua implementação significa a existência de vontade política para uma melhor gestão ambiental na esfera local.

\section{Metodologia}

\section{Área de estudo e fonte dos dados}

A área geográfica do estudo abrange 1.134 municípios do Semiárido brasileiro, segundo a delimitação adotada pelo IBGE. Os dados analisados são de origem secundária e representam uma escala municipal. $O$ ano de referência é 2009 para os indicadores de gestão municipal.

\section{Métodos de análise}

A análise dos municípios do semiárido quanto ao nível de adoção de gestão ambiental foi realizada a partir da construção de um índice resultante da agregação de um conjunto de indicadores representando instrumentos de gestão. De acordo com Mainali et al. (2014), o uso de índices agregados é adequado quando se quer captar diferentes dimensões de um conceito. Além disso, é uma escolha acertada quando se quer comparar unidades espaciais distintas, no caso, municípios (Freudenberg, 2003). Assim, o Índice de Gestão Ambiental (IGA) a partir de um conjunto de indicadores cuja seleção considerou critérios como: i) consistência teórica, ii) disponibilidade de dados para todos os municípios, e iii) confiabilidade das fontes (Booysen, 2002; Jacobs e Goddard, 2007; Braga, 2012). Os indicadores selecionados na Tabela 1.

Tabela 1. Sistema de indicadores do Índice de Gestão Ambiental (IGA).

\begin{tabular}{|l|}
\hline Indicador \\
\hline Conselho Municipal de Meio Ambiente \\
\hline Fundo Municipal de Meio Ambiente \\
\hline Financiamento de Ações e Projetos para Questões Ambientais pelo Fundo Municipal de Meio Ambiente \\
\hline Presença de Instrumento de Cooperação com órgão Estadual para licenciamento ambiental \\
\hline Consórcio Intermunicipal \\
\hline Existência de Comitê de Bacia Hidrográfica \\
\hline
\end{tabular}

Fonte: IBGE - Pesquisa de Informações Básicas Municipais. 
A agregação dos seis indicadores seguiu uma lógica binária, sendo atribuído valor 1 (um) quando observada a sua presença na gestão municipal e valor 0 (zero), se inexistente, conforme estudos de

$$
I G A{ }_{i}=\frac{1}{r} \sum_{g=1}^{r} I_{g i}
$$

Sendo:

$\mathrm{IGA}_{\mathrm{i}}=$ Índice de Gestão Ambiental no i-ésimo município.

$\mathrm{r}=$ número de indicadores componentes do IGA $(\mathrm{n}=6)$.

Igi $=$ Valor correspondente ao indicador g no no i-ésimo município ( 0 ou 1$)$.

$\mathrm{g}=1, \ldots, \mathrm{r}$ corresponde aos indicadores componentes do IGA $(1, \ldots, 6)$.

$\mathrm{i}=1, \ldots, \mathrm{n}$ corresponde ao número de municípios do semiárido $(\mathrm{n}=1.134$ ).

O IGA também pode ser interpretado como 0 percentual de implementação de instrumentos de gestão ambiental no município. Valores nulos significam que o município não adota qualquer um dos instrumentos avaliados. Por outro lado, valores unitários apontam que os seis instrumentos avaliados foram implementados.

Com o propósito de obter uma visualização mais clara dos resultados e por

se tratar de um número muito grande de municípios, os índices calculados foram submetidos à análise de agrupamento (método não hierárquico $k$-médias). A análise de agrupamento permitiu definir os intervalos de três classes usadas para agrupar os municípios (Tabela 2).

Para a análise da distribuição espacial da característica estudada foi elaborado, ainda, um mapa temático com o auxílio computacional do software ArcGis.

Tabela 2. Definição das classes de municípios segundo a implementação de instrumentos de gestão ambiental. 2010.

\begin{tabular}{lc}
\hline \multicolumn{2}{c}{ Classes do Índice de Gestão Ambiental } \\
\hline Menores níveis de implementação de instrumentos de gestão ambiental & 0,000 a 0,167 \\
Níveis intermediários de implementação de instrumentos de gestão ambiental & 0,333 a 0,500 \\
Maiores níveis de implementação de instrumentos de gestão ambiental & 0,501 a 1,000 \\
\hline
\end{tabular}

\section{Resultados e discussão}

Segundo Moises (1999), o poder público municipal pode atuar em duas frentes na promoção do desenvolvimento: uma interna e outra externa. Para o autor, a externa corresponde a sua interação com demais interessados no desenvolvimento local. Nessa frente, entende-se a cooperação entre os agentes, a articulação regional e a coordenação institucional com vistas ao melhor aproveitamento das potencialidades. Quanto à frente interna, entende-se as ações que dependem de sua própria vontade. Os instrumentos de gestão ambiental avaliados podem ser vistos como facilitadores da atuação dos municípios nas duas frentes citadas, haja vista refletirem meios de integração com outros agentes (consórcios municipais e comitês de bacia) e, ainda, opções particulares como a criação de conselho ou fundo municipal de meio ambiente.

Nota-se, no entanto, que o uso de instrumentos de gestão ambiental não é uma prática comum nos municípios do semiárido. A maioria dos municípios (622) 
encontra-se na classe com os menores níveis de implementação $(0,000 \leq$ IGA $\leq 0,167)$, o que significa no máximo 1 dos 6 instrumentos avaliados implementados pela prefeitura (Tabela 3).

A análise desagregada do índice aponta que o financiamento de ações e projetos para a adoção de questões ambientais é uma prática quase ausente nas prefeituras do semiárido. Considerando-se a região como um todo, somente $4 \%$ dos municípios adota este instrumento. Este resultado não é surpreendente, haja vista a falta de recursos comumente verificada nos municípios da região. Esse fato, muitas vezes, é usado como argumento para a omissão do governo local perante as questões ambientais. Por outro lado, a participação em comitês de bacias é uma característica observada em 56,3 dos municípios, sendo este o instrumento de gestão mais frequente.

Os comitês de bacias hidrográficas são os instrumentos de gestão ambiental mais frequente nos municípios. As bacias hidrográficas são as unidades de planejamento das ações implementadas no âmbito do Plano Nacional de Recursos Hídricos (Nascimento, 2010). Segundo Rodrigues (2014), trata-se de um órgão colegiado composto por representantes municipais da sociedade civil, usuários do setor privado e poder público municipal, estadual e federal.

O argumento de falta de recursos financeiros não pode ser usado para justificar a ausência de Conselho Municipal do Meio Ambiente. Os conselhos municipais são instrumentos democráticos que permitem a participação popular nos processos decisórios. Para Carvalho et al. (2005), trata-se de um espaço de negociação de interesses e demandas ambientais. A participação popular é especialmente importante nas discussões relativas ao meio ambiente. Mas apesar da relevância supracitada, apenas 39,3\% dos municípios do semiárido implementaram seus conselhos.

A quase totalidade dos 113 munícipios presentes na classe mais elevada de IGA $(97,3 \%)$ possui o instrumento, porém essa condição é observada somente em $10,1 \%$ dos municípios da primeira classe. Conforme Leme (2001) as prefeituras não têm motivação para a implementação de conselhos municipais de meio ambiente, pois, ao contrário de outros conselhos, como na área de saúde, não existe transferência de recursos ligados a sua existência. Geralmente os conselhos ambientais são instrumentos sem grandes resultados em decorrência da omissão da União como financiadora da política ambiental (Arretche, 2006). No entanto, considerando-se anos mais recentes esperase que atualmente exista uma maior quantidade de conselhos dado que a Lei Complementar $n^{\circ} 140 / 2011$, estabeleceu a existência de Conselhos Municipais de Meio Ambiente como condição para o município proceder ao licenciamento ambiental de atividades de impacto local.

Dada a dificuldade de obtenção de meios para o financiamento de ações ambientais, o Fundo Municipal do Meio Ambiente surge como fonte de recursos para a execução de ações para preservação e conservação ambiental, a partir de dotações da administração pública, setor privado, organizações não governamentais nacionais e internacionais. No entanto, a existência de Fundo Municipal de Meio Ambiente é rara na área de estudo (presente em apenas 15,6\% dos municípios). Uma justificativa para isso consiste na dificuldade para se implementar fundos municipais. De acordo com Carvalho et al. (2005), a criação de fundos deve ser autorizada por lei e as normas para tal constam na Lei Federal $n^{\circ} 4.320 / 1964$, nos artigos 71 a 74 . Ausência de fundos municipais de meio ambiente privam o município da arrecadação de pagamentos de multas por crimes ambientais previstas na Lei $\mathrm{n}^{\circ} \quad$ 9.605/1998 (Lei de Crimes Ambientais), sendo os valores, quando arrecados, destinados ao estado ou à união.

A Figura 1 sintetiza bem a condição do semiárido quanto aos seis instrumentos abordados neste estudo. Como já discutido, a maior importância é dada aos Comitês de Bacia Hidrográfica. Esse destaque sugere que a água ainda é a maior preocupação no semiárido. 
A maioria dos esforços, ainda que escassos, são voltados essencialmente para a mobilização dos municípios em torno da gestão de uso, preservação e recuperação de seus bens mais valiosos: os recursos hídricos. Os Comitês de Bacias Hidrográficas, no exercício de suas funções, atuam na segurança e na manutenção de reservas biológica, área de proteção ambiental, refúgios da vida silvestre, ou seja, áreas que apresentam relevante interesse para assegurar o abastecimento hídrico dos municípios.

Tabela 3. Implementação de instrumentos de gestão ambiental (percentual de municípios por classes identificadas). Municípios do Semiárido. 2009.

\begin{tabular}{|c|c|c|c|c|}
\hline \multirow{2}{*}{ Indicador do IGA } & \multicolumn{3}{|c|}{$\begin{array}{l}\text { Classes de Gestão Ambiental segundo o valor do } \\
\text { índice calculado }\end{array}$} & \multirow{2}{*}{ Semiárido } \\
\hline & $\begin{array}{c}0,000 \leq \mathrm{IGA} \leq \\
0,167\end{array}$ & $\begin{array}{c}0,333 \leq \text { IGA } \leq \\
0,500\end{array}$ & $\begin{array}{c}0,667 \leq \mathrm{IGA} \leq \\
1,000\end{array}$ & \\
\hline $\begin{array}{llll}\text { Conselho } & \text { Municipal de } & \text { Meio } \\
\text { Ambiente } & & \end{array}$ & 10,1 & 68,4 & 97,3 & 39,3 \\
\hline $\begin{array}{l}\text { Fundo Municipal de Meio } \\
\text { Ambiente }\end{array}$ & 0,5 & 20,6 & 81,4 & 15,6 \\
\hline $\begin{array}{l}\text { Financiamento de Ações e Projetos } \\
\text { para Questões Ambientais }\end{array}$ & 0,0 & 2,3 & 31,9 & 4,0 \\
\hline $\begin{array}{l}\text { Presença de Instrumento de } \\
\text { Cooperação com órgão Estadual } \\
\text { para licenciamento ambiental }\end{array}$ & 7,6 & 41,9 & 72,6 & 26,1 \\
\hline Consórcio Intermunicipal & 1,6 & 20,3 & 44,2 & 12,4 \\
\hline $\begin{array}{l}\text { Existência de Comitê de Bacia } \\
\text { Hidrográfica }\end{array}$ & 35,4 & 79,2 & 90,3 & 56,3 \\
\hline Número de municípios na classe & 622 & 399 & 113 & 1.134 \\
\hline Proporção de municípios na classe & 55,0 & 35,1 & 9,9 & 100,0 \\
\hline
\end{tabular}

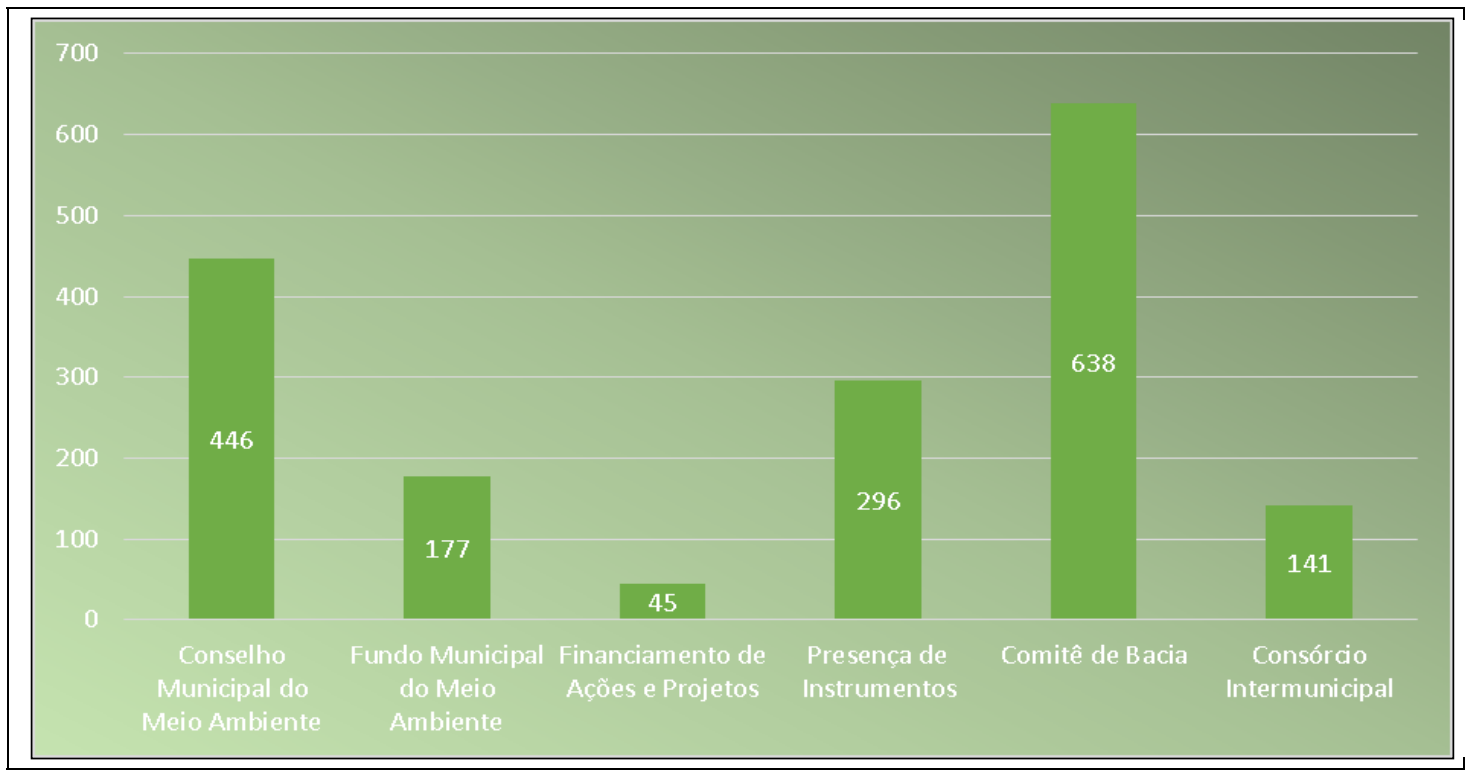

Figura 1. Número de municípios do Semiárido, por instrumento de gestão ambiental implementado. 
O Semiárido Brasileiro corresponde a um espaço geográfico de grande heterogeneidade. Os municípios aí inseridos guardam particularidades, mas certamente são percebidos subespaços com nítidas diferenças econômicas, sociais e culturais. O mesmo se observa no contexto da implementação de instrumentos de gestão municipal do meio ambiente. Como se observa na Figura 2, Piauí, Alagoas, Paraíba e Rio Grande do Norte apresentam menores níveis de gestão, sendo notória a carência dos instrumentos avaliados também em muitos municípios baianos.

O baixo nível de gestão ambiental somado aos efeitos da degradação alerta para uma maior severidade da pressão antrópica sobre os recursos naturais dos municípios uma vez que os instrumentos de enfrentamento e controle do processo são, de fato, escassos.

No âmbito municipal, é dever das prefeituras dispor de instrumentos capazes de prover a conservação dos recursos naturais. Sendo necessário, portanto, a cobrança das devidas intervenções dos responsáveis legais pela gestão do município para organização de uma estrutura eficiente na preservação dos recursos ambientais.

No âmbito da convivência com as secas difundida entre os municípios do semiárido, a gestão se mostra importante também no sentido de reduzir as vulnerabilidades socioeconômicas das populações rurais. No entanto, como se pensar em melhor qualidade na administração ambiental quando são observados níveis tão baixos de adoção de instrumentos de gestão?

$\mathrm{O}$ estudo mostrou que os modelos de gestão do meio ambiente nos municípios do semiárido brasileiro apresentam fragilidades inerentes ao baixo nível de implementação de instrumentos de gestão. Em termos gerais isso significa que o município reduz sua capacidade de interferir positivamente no uso dos recursos naturais no SAB.

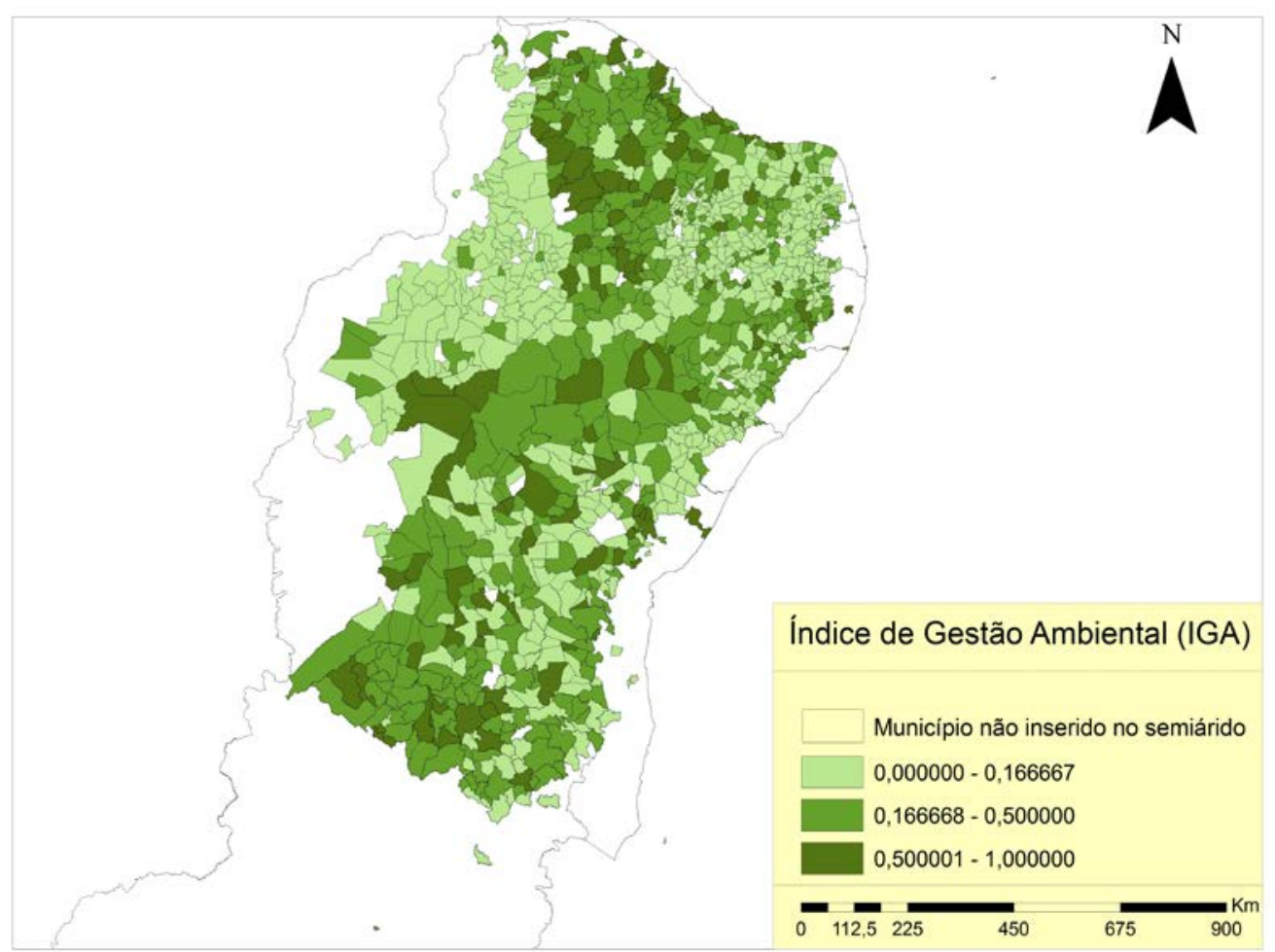

Figura 2. Distribuição espacial do Índice de Gestão Ambiental (IGA) nas classes identificadas. Municípios do Semiárido. 2009. 


\section{Considerações finais}

Como todo índice agregado o IGA, apresentou limitações (não agregou todos os instrumentos de gestão ambiental disponíveis na administração pública e não conseguiu captar aspectos qualitativos da gestão), mas teve o mérito de alertar para a omissão do governo municipal no que diz respeito à implementação de mecanismos úteis na solução de problemas ambientais.

No âmbito da capacidade administrativa das prefeituras do semiárido, observou-se um nível muito baixo de implementação de instrumentos de gestão ambiental. Considerando-se os Conselhos Municipais de Meio Ambiente e Comitês de Bacias Hidrográficas, como os instrumentos que melhor representam a participação popular nos processos de tomada de decisão e planejamento de políticas públicas, foi possível perceber que a população é pouco participativa. Também existe carência de integração interregional via consórcios intermunicipais. $\mathrm{O}$ município perde, ainda, quando em decorrência da inexistência de fundo municipal de meio ambiente, deixa de arrecadar recursos que poderiam ser aplicados em ações voltadas para a preservação, manutenção e recuperação de recursos naturais.

\section{Agradecimentos}

Ao Conselho Nacional de Desenvolvimento Científico e Tecnológico (CNPq). O artigo foi elaborado no âmbito do Projeto Distribuição Espacial da Vulnerabilidade à Desertificação nos Municípios do Semiárido, aprovado na Chamada Universal MCTI/CNPq $n^{\circ}$ $14 / 2012$.

\section{Declaração de conflito de interesses}

Os autores declaram não haver conflito de interesses.

\section{Referências}

ANA - Agência Nacional de Águas. O Comitê de Bacia Hidrográfica: o que é e o que faz? Brasília: ANA/SAG, 2011.

Andrade, A. J. P.; Souza, C. R.; Silva, N. M. A vulnerabilidade e a resiliência da agricultura familiar em regiões semiáridas: o caso do Seridó Potiguar. CAMPO-TERRITÓRIO: Revista de Geografia Agrária, v. 8, n. 15, p. 1-30, 2013.

Arretche, M. Uma contribuição para fazermos avaliações menos ingênuas. In: Barreira, M. C. R. N.; Carvalho, M. C. B. (Orgs.). Tendências e perspectivas na avaliação de políticas e programas sociais. São Paulo: IEE/PUC, 2001.

Bitar, O. Y.; Ortega, R. D. Gestão ambiental. In: ABGE. Geologia de Engenharia. São Paulo: ABGE, 1998. v. 32, p. 499-508.

Booysen, F. An overview and evaluation of composite indices of development. Social Indicators Research, v. 59, n. 2, p. 115-151, 2002.

http://dx.doi.org/10.1023/A:1016275505152

Braga, P. B. Análise do Programa Selo Município Verde como uma ferramenta operacional na gestão ambiental no Estado do Ceará. Fortaleza: Universidade Federal do Ceará, 2012. (Dissertação de mestrado).

Brose, M. Desenvolvimento local: uma conceituação empírica. Ijuí: Ed. Unijuí, 2004.

Carvalho, A. C.; Lima, P. V. P. S.; Sousa, R. P. A gestão municipal do saneamento básico no Estado do Ceará. Anais do VIII Encontro Regional da Sober: Pluralidades Econômicas, Sociais e Ambientais: Interações para Reinventar o Nordeste Rural, Parnaíba, 2013. Disponível em: <http://www.viiisoberne.com. br/anais/ARQUIVOS/GT3-100-93-

20130930154840.pdf>. Acesso em: 23 fev. 2016.

Carvalho, P. G. M.; Oliveira, S. M. M. C.; Barcellos, F. C.; Assis, J. M. Gestão local e meio ambiente. Ambiente \& Sociedade, v. 8, n. 1, p. 121-140, 2005. http://dx.doi.org/10.1590/S1414753X2005000100008

Chaves, L. C.; Freitas, C. L.; Ensslin, L.; Pfitscher, E. D.; Petri, S. M.; Ensslin, S. R. Gestão ambiental e sustentabilidade em 
instituições de ensino superior: construção de conhecimento sobre o tema. Revista GUAL, Florianópolis, v. 6, n. 2, p. 33-54, 2013. http://dx.doi.org/10.5007/19834535.2013v6n2p33

Freudenberg, M. Composite indicators of country performance. Paris: OECD, 2003.

IBGE - Instituto Brasileiro de Geografia e Estatística. Perfil dos Municípios Brasileiros2009. Rio de Janeiro: Pesquisa de Informações Básicas Municipais. Coordenação de População e Indicadores Sociais, 2010.

IPCC - Intergovernmental Panel on Climate Change. Climate Change 2007: Impacts, adaptation and vulnerability. In: Parry, M. L.; Canziani, O. F.; Palutikof, J. P.; van der Linden, P. J.; Hanson, C. E. (Eds.). Contribution of Working Group II to the Fourth Assessment Report of the Intergovernmental Panel on Climate Change. Cambridge, UK: Cambridge University Press, 2007.

Jacobs, R.; Goddard, M. How do performance indicators add up? an examination of composite indicators in public services. Public Money \& Management's, v. 27, n. 2, p. 103-110, 2007.

Leme, T. N. Os municípios e a Política Nacional do Meio Ambiente. Planejamento e Políticas Públicas, v. 2, n. 35, p. 25-52, 2011.

Lima, P. V. P. S.; Sousa, J. S.; Araújo Sobrinho, A. M.; Faustino, J. C. S.; Casimiro Filho, F. Gestão municipal da segurança pública: responsabilidade dos municípios brasileiros no combate à violência. Revista Políticas Públicas, v. 18, $\quad$ n. 2, p. 399-414, 2014. Disponível em: <http://www.revistapoliticas publicas.ufma.br/site/download.php?id_publicac ao=965> . Acesso em: 23 fev. 2016.

Mainali, B.; Pachauri, S.; Rao, N. D.; Silveira, S. Assessing rural energy sustainability in developing countries. Energy for Sustainable Development, v. 19, p. 15-28, 2014. http://dx.doi.org/10.1016/j.esd.2014.01.008

Marengo, J. A.; Alves, L. M.; Beserra, E. A.; Lacerda, F. F. Variabilidade e mudanças climáticas no semiárido brasileiro. In: Medeiros, S. S.; Gheyi, H. R.; Galvão, C. O.; Paz, V. P. S. (Orgs.). Recursos hídricos em regiões áridas $\mathrm{e}$ semiáridas. Campina Grande: INSA, 2011. p. 383-422.

Milaré, E. Sistema Municipal do Meio Ambiente - SISMUMA: instrumentos legais e instituições de ensino superior: construção de econômicos. Revista de Direito Ambiental, n. 14, 1999.
Miranda, G. M. Indicadores do potencial de gestão municipal de gestão municipal de recurso hídrico. Rio Claro: Universidade Estadual Paulista Júlio de Mesquita Filho, 2012. (Dissertação de mestrado).

MMA. Ministério do Meio Ambiente. Conselho Municipal de Meio Ambiente - CMMA. Disponível em: <http://www.mma.gov.br/ port/conama/conselhos/conselhos.cfm>. Acesso em: 13 abr. 2016.

Moisés, H. N. Município-Rede: planejamento, desenvolvimento político e sustentabilidade. O município no século XXI: cenários e perspectivas. São Paulo: Fundação Prefeito Faria Lima-CEPAM, 1999.

Moraes, A. C. R. Ordenamento territorial: uma conceituação para o planejamento estratégico. In: Ministério da Integração Nacional. Para pensar uma política nacional de ordenamento territorial: anais da oficina de sobre a Política Nacional de Ordenamento Territorial. Brasília: Ministério da Integração Nacional, 2003.

Nascimento, F. R. Conceitos e teorias sobre desertificação em bacias hidrográficas subsídios para abordagens metodológicas. Anais do VI Seminário Latinoamericano de Geografia Física e do II Seminário Ibero-Americano de Geografia Física, Universidade de Coimbra, Coimbra, Maio, 2010.

Oliveira, M. R. R.; Rodrigues, C. B.; Casimiro Filho, F. Gestão ambiental e propensão socioeconômica à desertificação nos municípios do Semiárido Brasileiro. Anais do $53^{\circ}$ Congresso da SOBER - Agropecuária, Meio Ambiente e Desenvolvimento, João Pessoa, 2015.

Perez, I. C.; Bourguignon, M. A. B.; Corrêa, R. G. (Org.). Conselhos municipais de meio ambiente: orientações para implementação. Rio de Janeiro: INEA - Instituto Estadual do Ambiente, 2015.

Rodrigues, C. R. Indicadores para avaliação de comissões gestoras de sistemas hídricos e sua aplicação na análise das Bacias da Região Metropolitana de Fortaleza. Fortaleza: Universidade Federal do Ceará, 2014. (Dissertação de mestrado).

Sabbagh, R. B. Gestão ambiental. São Paulo: Secretaria do Meio Ambiente, 2011.

Sousa, M. C.; Lima, P. V. P. S.; Khan, A. S. Mecanismos de gestão municipal e a promoção dos direitos humanos. Revista de Administração Pública, v. 49, n. 4, p. 9851009, 2015. 
Tinoco, J. E. P.; Kraemer, M. E. P. Contabilidade e gestão ambiental. São Paulo: Atlas, 2004.

Vaz, J. C. Consórcios intermunicipais. Dicas: ideias para ação municipal. PÓLIS, São Paulo, n. 97, 1997.

Vieira, J. T.; Weber, E. O licenciamento ambiental como forma de efetivação da autonomia municipal e do desenvolvimento sustentável. Jus Navigandi, Teresina, ano 13, n. 1731, 28 mar. 2008. Disponível em: $<$ https://jus.com.br/artigos/11099/o-

licenciamento-ambiental-como-forma-deefetivacao-da-autonomia-municipal-e-dodesenvolvimento-sustentavel/>. Acesso em: 22 jul. 2012.

Informação da Licença: Este é um artigo Open Access distribuído sob os termos da Licença Creative Commons AtribuiçãoSemDerivações-SemDerivados, que permite o download do trabalho e o compartilhamento desde que seja atribuído o devido crédito, mas sem que possa ser alterado de nenhuma forma ou utilizá-los para fins comerciais. 